\title{
Rock-Breaking Performance of Cutters of Tunnel Boring Machine in Broken Coal Rock Formation
}

\author{
Zhenggang Guo ${ }^{1}$, Shuai Lv ${ }^{1}$, Juan Wang ${ }^{1}$, Xu Zhang ${ }^{2 *}$ \\ ${ }^{1}$ Department of Mechanical Engineering, Dalian University of Technology, Dalian 116023, China \\ ${ }^{2}$ Institute of Mechanical Engineering and Automation, Dalian Polytechnic University, Dalian 116023, China
}

Corresponding Author Email: zhangxu@dlpu.edu.cn

https://doi.org/10.18280/ijsse.100103

Received: 20 May 2019

Accepted: 26 October 2019

\section{Keywords:}

broken coal rock, discontinuous cutting, rock-breaking performance, finiteelement analysis, cutters

\begin{abstract}
This paper aims to design a suitable method to analyze the relationship between the rockbreaking performance and tunneling performance of the cutters of tunnel boring machine (TBM). Considering the cutting discontinuity in broken coal rock formation, the authors put forward a simulation method for the rock-breaking performance of TBM cutters. The material properties of broken coal rock with low mechanical strength and poor uniformity were described by a linear elastic constitutive model and a Drucker-Prager plastic model. The variations in the cutting force with cutting depths $(5,10$ and $15 \mathrm{~mm})$ and rake angles $(5,10$ and $15^{\circ}$ ) were observed through the simulations, aiming to disclose the mechanical nature of the contact, extrusion and peeling of the coal rock under the action of the cutter. The results show that a high cutting depth and a small rake angle are favorable for tunneling efficiency, but unfavorable for tunneling safety. Overall, the optimal cutting parameters were determined as the cutting depth of $10 \mathrm{~mm}$ and rake angle of $15^{\circ}$. Our simulations were proved valid through comparison with the results of Evans' cutting resistance model for wedge cutters. The research results shed new light on the research into the TBM cutting of unstable coal rock.
\end{abstract}

\section{INTRODUCTION}

The frequent accidents in coalmines are a bottleneck of the healthy development of the energy sector. Once a coalmine collapse, it is urgent to reduce casualties by setting up a life support and rescue channel. This calls for the research and development (R\&D) of coalmine rescue equipment that can rapidly construct rescue channels. In addition to rock-breaking, a common function of mining equipment, the coalmine rescue equipment should also be able to tunnel safely into the collapsed coal seams.

Failing to eliminate the safety hazards in tunneling, the existing rock-breaking methods cannot be applied in the coalmine rescue equipment, namely, pick cutting [1], water jet breaking [2], laser breaking [3, 4] and ultrasonic vibration and drilling $[5,6]$.

Tunnel boring machine (TBM) is professional equipment for rock tunneling [7]. The TBM works by spinning its cutterhead into the heading face, while squeezing and cutting the rock with the cutters on the cutter-head [8]. There are many advantages of TBM tunneling, including fast velocity, wide application, and high stability $[9,10]$. Therefore, the TBM has been widely considered to set up coalmine rescue channels.

Despites its advantages, the TBM as coalmine rescue equipment faces some technical challenges. Unlike normal formations of TBM tunneling, the collapsed coal rock formation is highly discontinuous, and is prone to secondary disaster under the cutting disturbance. The TBM mainly relies on the cutters to break the rocks. Before the R\&D of coalmine rescue equipment, it is highly necessary to explore the rockbreaking mechanism of collapsed coal rock formation, and disclose the effect of each cutter parameter on tunneling performance and rock stability under rock-breaking.
Nevertheless, there is no theoretical or experimental research of coal rock breaking by cutters.

In terms of rock models, Liu et al. [11] successfully conducted finite-element analyses on the generation and expansion of rock indentations and cracks under the action of cutters, in the light of the Drucker-Prager yield criterion. Qiao et al. [12] created a reasonable coal rock constitutive model based on empirical formulas and previous experiments, and numerically simulated the coal rock cutting with conical picks. $\mathrm{Gu}$ and Ozbay [13] developed a numerical model of a double shear test device, and used the model to examine how the interface between coal seam and surrounding rock affects the failure stability of the side wall and coalface in the mining environment. The above experimental and theoretical research clearly manifests rock properties, providing the modelling methods and data supports for our analysis on the cutting performance of coal rock.

In terms of the rock-breaking mechanism of TBM cutters, Menezes et al. [14] simulated the mechanical rock-breaking process on finite-element software LS-DYNA. Li et al. [15] developed a finite-element model for the cutting process of rock and soil, and specified the way to analyze the cutter-rock interaction. Rostami and Chang et al. [19] described the general method for the optimal design of the cutter-head, and provided several design patterns. Innaurato et al. [17] investigated how the TBM cutters interact with the rock under high stress, and obtained the law of rock fragmentation. Geng et al. [18] studied the rock-breaking mechanism of disc cutter in the presence of free surface, and proposed a free-surfaceassisted rock-breaking method for the cutter-head of multistage heading machine. Cardu et al. [9] compared and corrected the Colorado School of Mines (CSM) model and the Norwegian University of Science and Technology (NTNU) 
model through experiments.

Farrokh and Kim [19] discussed the cutter wear and cutterhead intervention interval of hard rock TBM. Bilgin et al. [20] compared the mechanical properties of chisel tools and disc cutters under complex geological conditions. With the aid of AUTODYN-3D, Jung-Woo Cho et al. [21] analyzed the effect of optimal spacing of TBM disc cutters on rock-breaking. Maji and Theja [22] designed a new TBM tunneling performance prediction model, using the data measured from tunnel engineering. Rojek [23] created a thermodynamic discrete element model to simulate the coal rock cutting of road-header picks. Munoz et al. [24] tested the cutting of different types of rocks under uniaxial compression, and examined the inherent specific energy and strain energy in the cutting process. The above studies have clarified the principles, simulation methods and experiment analyses, laying a solid basis for our research on the coal rock cutting mechanism.

In the field of tunnel rescue, it is an emerging research direction to construct coalmine rescue channels through TBM tunneling. However, the relevant research is bottlenecked by the insufficient understanding of coal rock breaking mechanism. Most of the existing studies on TBM tunneling are concentrated on the mechanism of rock-breaking. The few reports on coal rock cutting only tackle the coal rock cutting by road-header picks.

Drawing on the previous studies on TBM rock-breaking mechanism, this paper aims to establish an analytical method for the rock-breaking process of TBM cutters in broken coal rock, in view of the instability of the broken coal rock in collapsed coalmine, and also identify the relationship between rock-breaking performance of the TBM cutters and the tunneling performance of the equipment. The research results shed new light on the research of TBM rock-breaking mechanism in broken coal rock.

Using a linear elastic constitutive model and a DruckerPrager plastic model, this paper defines the material properties of broken coal rock, simulates the breaking mode and process of broken coal rock under the action of cutters, and explores the influence of cutter parameters on TBM tunneling. On this basis, the optimization criteria for TBM cutter parameters were put forward to strike a balance between tunneling efficiency and safety in broken coal rock.

\section{MECHANICAL MODEL FOR TBM CUTTING OF COAL ROCK}

Under the action of TBM cutters, the coal rock mainly suffers from tensile failure. Hence, the mechanical model for TBM cutting of broken coal rock formation was established based on Evans' cutting resistance model for wedge cutters [25].

When a cutter cuts the coal rock, the tensile crack will develop along an arc-shaped trajectory from the tool nose to the free surface, i.e. the surface that the cutter does not directly contact with or act on. The total tensile stress must be perpendicular to the trajectory and passes through the center of the arc. In the contact area between the cutter and coal rock, a great contact stress will be generated in a small volume, creating a dense core near the front of the cutter.

Before modelling, the following two hypotheses were put forward:
(1) The coal rock is broken by the tensile stress, and the rock-breaking follows the maximum tensile stress failure theory.

(2) The resultant force $T$ of the tensile stress on the broken surface passes through the center of the arc and bisects the arc angle. As shown in Figure 1, the shape of the dense core is delineated by arc AG and line AK. The center and radius of the arc AG are O' and a, respectively.

Based on the Evans' model and the above hypothesis, the mechanical model for TBM cutting of coal rock (Figure 1) was constructed, in the light of the cutter-rock friction and the vertical thrust of the cutter.

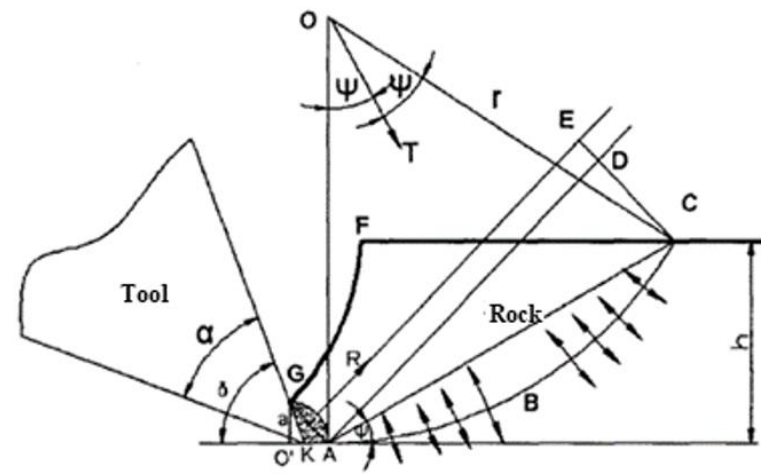

Figure 1. The mechanical model for TBM cutting of coal rock

For a cutter with the width of 1 , the resultant force that passes through the dense core and acts on the central block can be described as:

$$
R=2 \int_{0}^{\frac{\pi}{4}} a \sigma_{c} \cos \theta=\sqrt{2} a \sigma_{c}
$$

where, $\sigma_{\mathrm{c}}$ is the uniaxial compressive strength of rock. If the force is sufficiently large, the rock block will break under the tensile force along the arc $\mathrm{ABC}$ with the breaking angle $\Psi$. The ultimate tensile force depends on the tensile strength of the rock:

$$
T=\sigma_{t} \cdot r \cdot \int_{-\Psi}^{\Psi} \cos \beta d \beta=2 \sigma_{t} \sin \psi=\frac{\sigma_{t} h}{\sin \psi}
$$

where, $T$ is the ultimate tensile force per unit width; $\sigma_{t}$ is the uniaxial tensile strength of rock; $\Psi$ is the broken angle; $h$ is the cutting depth. According to the moment balance of forces $\mathrm{R}$ and $\mathrm{T}$ to point $\mathrm{C}$ and the geometric relationship in Figure 1, the balance equation can be obtained as:

$$
R\left[\frac{\sqrt{2}}{2} a+\frac{h}{\sin \psi} \cos \left(\psi+\frac{\pi}{4}\right)\right]-T \frac{h}{2 \sin \psi}=0
$$

Substituting the values of $\mathrm{R}$ and $\mathrm{T}$ into Eq. (3), the radius of arc $A G$ can be derived from $\mathrm{a} / \mathrm{h}>0$ :

$$
a=\frac{\sqrt{\frac{\sigma_{c} \cos ^{2}\left(\frac{\pi}{4}+\psi\right)+\sigma_{t}}{\sigma_{c}}}-\cos \left(\frac{\pi}{4}+\psi\right)}{\sqrt{2} \sin \psi} h
$$


According to the principle of minimum energy, $d(a / h) /$ $d \Psi=0$ holds when the rock breaks. Taking the derivative of Eq. (6) with respect to $m=\frac{\sigma_{t}}{\sigma_{c}}$, we have:

$$
\begin{gathered}
\left(m^{2}+2 m+2\right) \cos ^{2} 2 \psi+2 m(m+1) \cos 2 \psi+m^{2} \\
-1=0
\end{gathered}
$$

According to the theory of rock mechanics, the rock breaking angle $\Psi$ is smaller than $\pi / 4$. Solving Eq. (5), we have:

$$
\psi=\frac{1}{2} \arccos \left[\frac{\sqrt{2\left(\sigma_{c}{ }^{4}+\sigma_{c}^{3} \sigma_{t}\right)}-\sigma_{t} \sigma_{c}-\sigma_{t}{ }^{2}}{\sigma_{t}{ }^{2}+2 \sigma_{t} \sigma_{c}+2 \sigma_{c}{ }^{2}}\right]
$$

For a cutter with the width of $b$, the resultant force that passes through the dense core and acts on the central block can be described as:

$$
R=\sqrt{2} a b \sigma_{c}
$$

The resultant force $R$ can be decomposed into a force parallel to the rake face and a force perpendicular to the rake face:

$$
\left\{\begin{array}{l}
R_{H}^{\prime}=R \sin \left(\delta-45^{\circ}\right) \\
R_{V}^{\prime}=R \sin \left(\delta-45^{\circ}\right)
\end{array}\right.
$$

The actual values of $R_{H}^{\prime}$ and $R_{V}^{\prime}$ are affected by the friction angle $\Phi$ between the cutter and the rock. According to the Evans' model, the actual values of $R_{H}^{\prime}$ and $R_{V}^{\prime}$ can be approximated by replacing $\left(\delta-45^{\circ}\right)$ in Eq. (9)-(10) with $\left(\delta-45^{\circ}+\phi\right)$ :

$$
\left\{\begin{array}{l}
R_{H}^{\prime}=R \sin \left(\delta-45^{\circ}+\phi\right) \\
R_{V}^{\prime}=R \sin \left(\delta-45^{\circ}+\phi\right)
\end{array}\right.
$$

Under the vertical thrust $F_{V}$, the cutter presses into the rock by a depth of $h$. In this case, the cutter must overcome the breaking strength of the rock, according to the theory on the indentation of rock by wedge-shaped tools. Hence, the vertical thrust can be illustrated as:

$$
\begin{array}{r}
F_{V}=2 b h \sigma_{c} \tan \frac{\alpha}{2}+R \cos \left(\delta-45^{\circ}+\phi\right) \cos \delta \\
+R \sin \left(\delta-45^{\circ}+\phi\right) \sin \delta
\end{array}
$$

where, $\alpha$ is the blade angle. Based on force balance, the following relationships can be derived:

$$
\begin{aligned}
& F_{H}-\mu N-R \cos \left(\delta-45^{\circ}+\phi\right) \sin \delta \\
& +R \sin \left(\delta-45^{\circ}+\phi\right) \cos \delta=0 \\
& 2 b h \sigma_{c} \tan \frac{\alpha}{2}+R \cos \left(\delta-45^{\circ}+\phi\right) \cos \delta \\
& +R \sin \left(\delta-45^{\circ}+\phi\right) \sin \delta-N \\
& =0
\end{aligned}
$$

where, $\mu$ is the coefficient of cutter-rock friction; $F_{H}$ is the horizontal cutting force; $F_{V}$ is the vertical thrust; $N$ is the reaction to vertical support. From Eqns. (6)-(15), the horizontal cutting force of the cutter can be obtained as:

$$
F_{H}=b h \sigma_{c} g \frac{\sqrt{\frac{\sigma_{c} \cos ^{2}\left(\frac{\pi}{4}+\psi\right)+\sigma_{c}}{\sigma_{c}}}-\cos \left(\frac{\pi}{4}+\psi\right)}{\sin \psi} g\left[\cos \left(\delta-45^{\circ}+f\right)(\mu \cos \delta+\sin \delta)+\sin \left(\delta-45^{\circ}+f\right)(\mu \sin \delta\right.
$$

\section{SIMULATION MODEL CONSTRUCTION AND PARAMETER SELECTION}

\subsection{Selection of constitutive model}

Unlike common reservoir rocks, the broken coal rock has many unique mechanical properties: small elastic modulus, large Poisson's ratio, low mechanical strength, developed cracks and cleats, as well as poor homogeneity. The DruckerPrager yield criterion, which considers the effect of intermediate principal stress on rock strength and that of hydrostatic pressure on yield strength, provides a suitable standard for computing the collapse of coalbed gas wells and simulating the mechanical behavior of collapsed coal rock. Therefore, this paper selects the linear elastic model to describe the constitutive relationship of broken coal rock suffering from elastic deformation under the action of cutters, and modifies the Drucker-Prager model to simulate the plastic constitutive relationship of the coal rock [26]. The yield surface used by the linear Drucker-Prager model is shown in Figure 2.

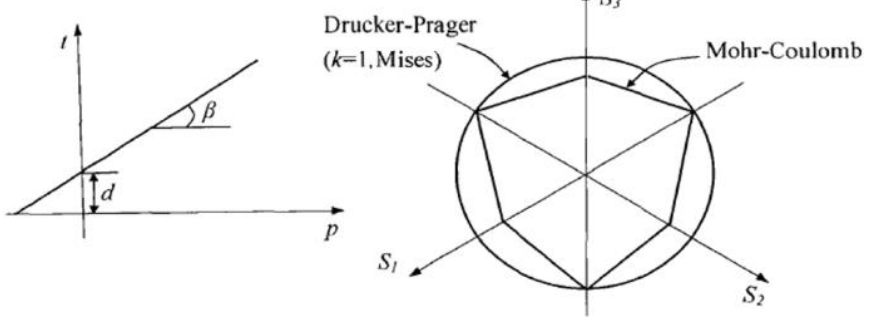

Figure 2. The shape of the Drucker-Prager model with a linear meridian on the $\pi$ plane

The yield function and the function of the elastic potential surface can be respectively expressed as:

$$
\begin{gathered}
F=t-p \tan \beta-d=0 \\
G=t-p \tan \varphi
\end{gathered}
$$

where,

$$
t=\frac{q}{2}\left[1+\frac{1}{k}-\left(1-\frac{1}{k}\right) \frac{r^{3}}{q}\right]
$$


where, $t$ is the biased stress; $p$ is the equivalent compressive stress; $\beta$ is the tilt angle of the linear yield surface in the stress space, which is related to the friction angle; $\varphi$ is the dilatancy angle; $\mathrm{q}$ is the equivalent (von Mises) stress; $r$ is the third invariant of the biased stress; $\mathrm{k}$ is the ratio of triaxial tensile strength to triaxial compressive strength, which reflects the effect of the second principal stress on yield; $d$ is the intercept of the yield surface on the $\mathrm{p}$ - $\mathrm{t}$ axis in the stress space, which represents the cohesion of the material. The $\mathrm{k}$ value must fall within $(0.778,1.0)$ to keep the yield surface a convex. The $d$ value can be determined as follows:

If the uniaxial compressive strength $\sigma_{c}$ is known:

$$
d=\left(1-\frac{1}{3} \tan \beta\right) \sigma_{c}
$$

If the uniaxial tensile strength $\sigma_{t}$ is known:

$$
d=\left(\frac{1}{k}+\frac{1}{3} \tan \beta\right) \sigma_{t}
$$

If the shear strength $\tau$ is known:

$$
d=\frac{\sqrt{3}}{2} \tau\left(1+\frac{1}{k}\right)
$$

\subsection{Construction of finite-element model}

Figure 3 presents a typical cutter on the TBM, which is the main tool for TBM tunneling. The mechanical model for TBM cutting of coal rock was constructed on ABAQUS. To improve the efficiency of finite-element simulation, the model was reasonably simplified into a $2 \mathrm{D}$ model.

Besides, a single coal rock $(200 \mathrm{~mm} \times 50 \mathrm{~mm})$ was obtained from the collapsed formation. The cutter length and height are $80 \mathrm{~mm}$ and $120 \mathrm{~mm}$, respectively. To optimize the cutting angle, three cutting angles, namely, $5^{\circ}, 10^{\circ}$ and $15^{\circ}$, were simulated at the cutting depth of $10 \mathrm{~mm}$. The relative position between cutter and coal rock was determined by the Translate command in the Assembly module of ABAQUS/CAE. The finite-Element model is displayed in Figure 4 below.

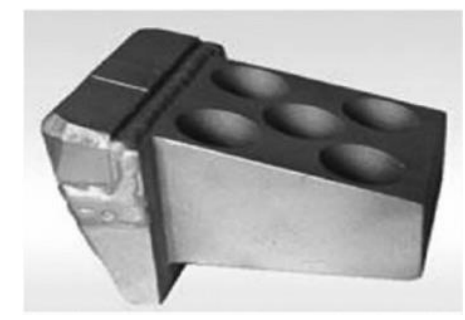

Figure 3. A cutter on the cutter-head of the TBM

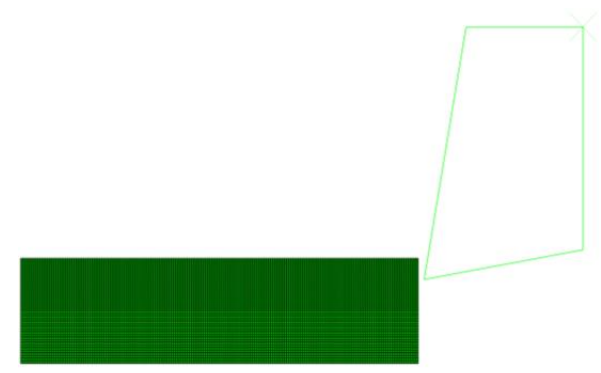

Figure 4. Finite-element model for TBM cutting of coal rock
The material parameters of cutter and coal rock were configured in the Property module of ABAQUS/CAE. Due to the high rigidity and strength of the cutter, the cutter deformation is negligible compared with that of coal rock, i.e. the cutter was regarded as a rigid body. The mechanical parameters of the coal rock are listed in Table 1.

Table 1. Material parameters of the coal rock for finiteelement simulation

\begin{tabular}{ccccc}
\hline $\begin{array}{c}\text { Elastic } \\
\text { modulus/MPa }\end{array}$ & $\begin{array}{c}\text { Poisson's } \\
\text { ratio }\end{array}$ & $\begin{array}{c}\text { Compressive } \\
\text { strength } / \mathbf{M P a}\end{array}$ & $\begin{array}{c}\text { Friction } \\
\text { angle }^{\circ}\end{array}$ & $\begin{array}{c}\text { Density } \\
\mathbf{k g} / \mathbf{m}^{\mathbf{3}}\end{array}$ \\
\hline 1,400 & 0.3 & 20.49 & 30.2 & 1,500 \\
\hline
\end{tabular}

During the cutting process, the cutter moves relative to the coal rock along the negative direction of the $\mathrm{X}$-axis in the coordinate system. Thus, the cutter movement in the $\mathrm{X}$ direction has no restriction on the degree of freedom (DOF) and gives the pick a velocity $\mathrm{V}$ in the negative direction of the $\mathrm{X}$-axis. The coal rock restricts the DOF of the cutter in the XY direction, keeping it stationary.

Through arbitrary Lagrangian-Eulerian (ALE) adaptive meshing, this paper decomposes the coal rock model into 9,800 tetrahedral solid elements (CPE4R). Considering the complex relationship between cutter and coal rock, the mesh seeds were positioned both globally and on the edges, aiming to improve computing accuracy and speed, and promote the quality of meshed grids.

\section{SIMULATION RESULTS AND ANALYSIS}

\subsection{Cutting mechanism}

Our simulations target the TBM cutting of coal rock under the given conditions. Through the simulations, the authors observed how the stress and deformation are distributed and evolved in the cutting process. The observed data were analyzed to disclose the mechanical nature of the contact, extrusion and peeling of the coal rock under the action of the cutter.

According to the Mohr-Coulomb theory [27] (Moran, Pantelides, \& Reaveley, 2019), the cutting force of a specific rock is mainly affected by cutting depth, cutting angle and cutter width. Since the cutter width is fixed, it is only necessary to explore the effects of cutting depth and rake angle on cutting force.

Figures 5 and 6 show the time variations of equivalent stress distribution and plastic deformation under a given set of conditions (cutting depth: 5mm; cutting angle: $10^{\circ}$ ), respectively. As shown in Figure 5, as the cutter pressed into the coal rock at a constant velocity, the rake face squeezed on the coal rock, and the stress concentrated on the contact between the coal rock and the rake face, making the contract one of the most stressed zones.

With the elapse of time, the cutter further squeezed on the coal rock, causing a continuous expansion of the stress concentration zone. The most stressed zones expanded from the rake face close to the tool nose (shear plane) to the upper surface of the coal rock near the shear plane.

Meanwhile, the stresses in these squeezed zones continued to grow, and the coal rock in these zones exhibited plastic deformation. Once the equivalent stress on the coal rock exceeds the threshold of the Drucker-Prager yield criterion, the coal rock broke into chips, which were forced to fly out. This 
marks the end of a cutting cycle. The plastic strain of the stressed zones at rock-breaking was greater than 0.8 (Figure $6)$.

The above analysis shows that the TBM cutting of coal rock can be divided into three phases:

(1) Deformation phase

In this phase, the coal rock undergoes elastic and plastic deformations under the action of cutter. The cutting force is stored in the coal rock as deformation energy. The load on the cutter increases dramatically as the cutting stress approaches the strength of the coal rock.

(2) Crack generation phase

When the cutter continues to move forward, the blade invades and presses into the coal rock. Under the action of the blade, the coal rock suffers from stress concentration. The blade-rock contact is squeezed and sheared to form a dense

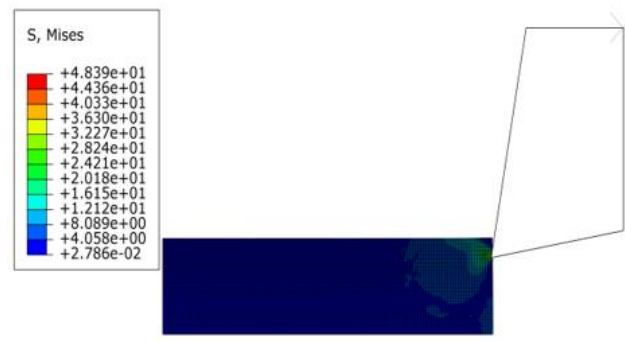

(a) $0.04 \mathrm{~s}$

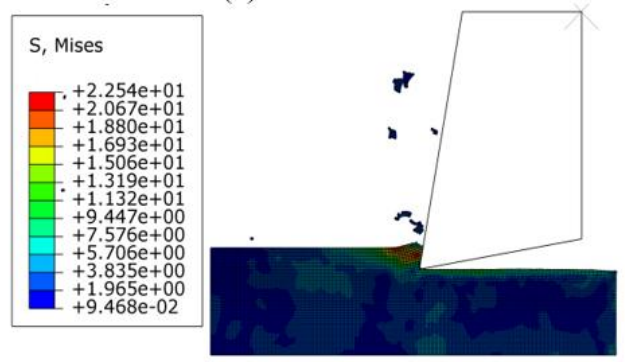

(c) $1 \mathrm{~s}$ core. The stored elastic energy is partly consumed in the local breaking. After that, the cutting force reaches the maximum, and cracks appear in the dense core, causing the cutting force to decrease.

(3) Crack propagation phase

When the cutter continues to move forward, the cracks propagate toward the free surface. In this case, the stress on the coal rock and the cutting force both decline. Finally, the cracks arrive at to the free surface, turning the coal rock into chips. In this way, the stress of the coal rock is completely released. In this phase, the cutting force and the deformation energy stored in the coal rock are converted into the surface energy of the coal rock. After the chips burst off the bedrock, the cutter is out of contact of the rock, and the cutting force is reduced to zero.

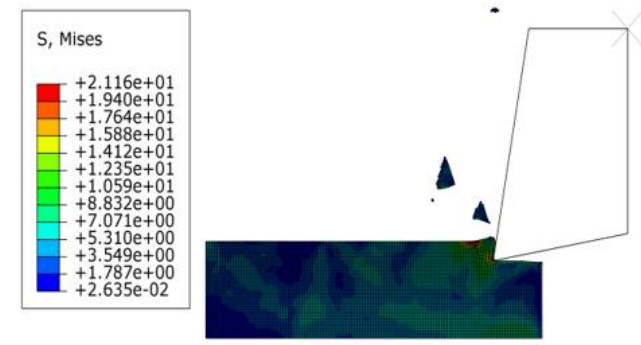

(b) $0.32 \mathrm{~s}$

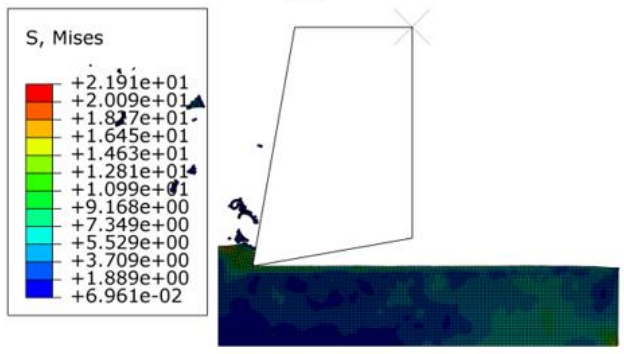

(d) $1.84 \mathrm{~s}$

Figure 5. Time variation in equivalent stress

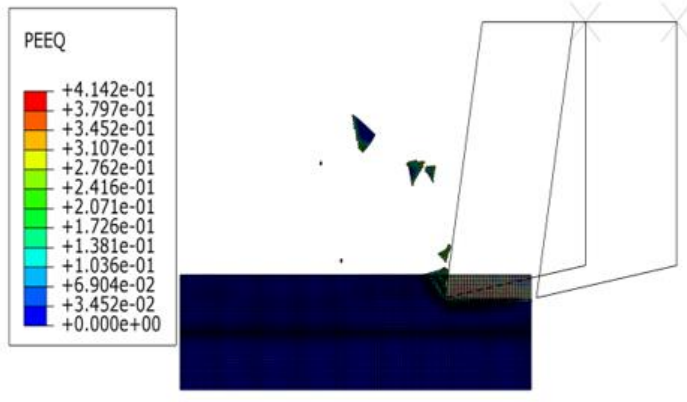

(a) $0.52 \mathrm{~s}$

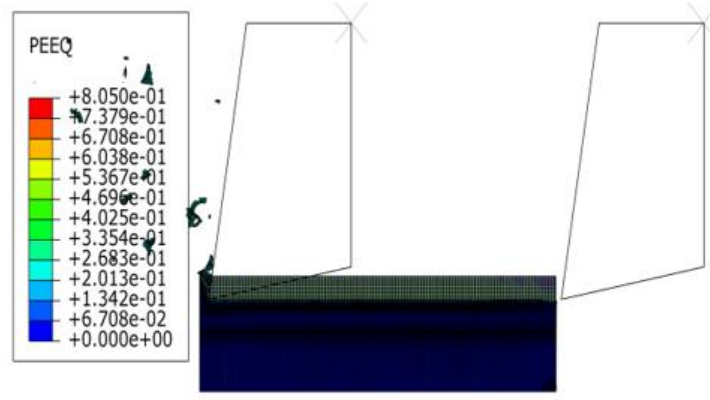

(b) $1.98 \mathrm{~s}$

Figure 6. Time variation in equivalent plastic strain

Coal rock is more brittle than soft rock. During the cutting process, the two types of rocks differ in the evolution of stress distribution and the formation of chips. Figure 7 compares the cutting failures of coal rock and soft rock. It can be seen that the cutting mechanism of coal rock is basically the same as that of soft rock. Of course, there are some differences in cutting behavior and chip properties, due to the variation in material properties. For the coal rock, the stress concentration zones were mainly distributed at the tool nose and on the free surface; after cutting, obvious fracture zones were formed, the chips were not uniform in size and shape, and secondary fracture zone appeared due to discontinuous cutting. For the soft rock, the cutting mainly produced a fracture line; the chips were shell-shaped or lenticular on the separation surface, and uniform in size and shape. These results show that, under the same cutting parameters, the tunneling efficiency and stability in coal rock are different from those in soft rock. 


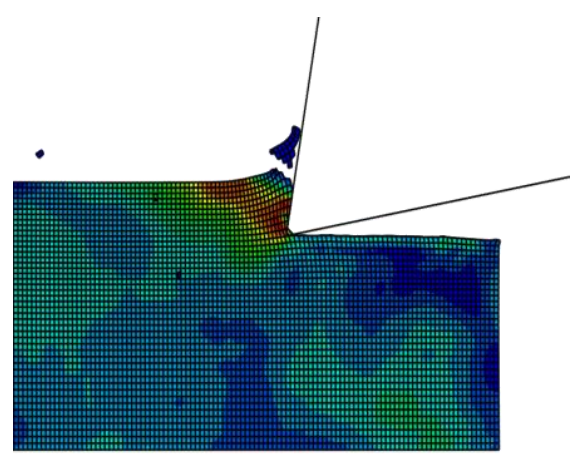

(a) Coal rock

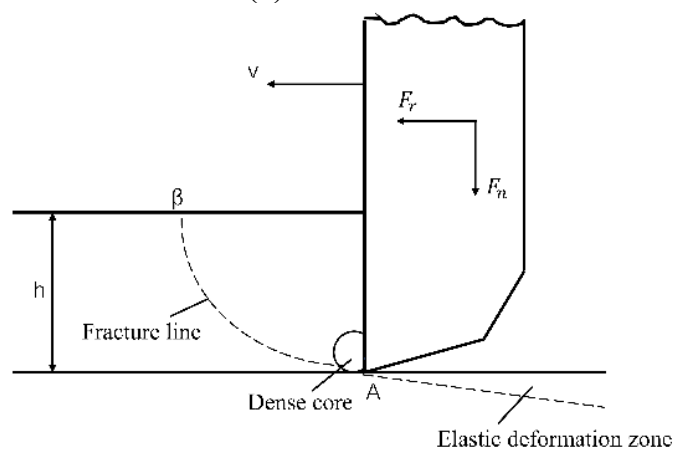

(b) Soft rock

Figure 7. Cutting failures of coal rock and soft rock

\subsection{Impacts of cutting parameters on cutting force}

During the cutting process, the chips of the coal rock peel off the bedrock under the cutting force. This force, provided by the cutter, is closely related to cutting efficiency. The impact of cutting force also directly bears on coalface stability. Thus, it is very meaningful to ascertain the influence and fluctuations of the cutting force.

As shown in Figure 2, finite-element simulations were conducted with three cutting depths $(5,10$ and $15 \mathrm{~mm})$ and three cutting angles $\left(5,10\right.$ and $\left.15^{\circ}\right)$, with the aim to disclose the influence mechanism of cutting depth and cutting angle on cutting force.

Figure 8 displays the variation in cutting force with cutting depths $(5,10$ and $15 \mathrm{~mm})$ at the fixed rake angle $\left(10^{\circ}\right)$; Figure 9 provides the variation in cutting force with rake angles (5, 10 and $\left.15^{\circ}\right)$ at the fixed cutting depth $(10 \mathrm{~mm})$; Table 2 lists the mean and peak cutting forces of each plan.

Table 2. Simulation results

\begin{tabular}{cccc}
\hline $\begin{array}{c}\text { Rake } \\
\text { angle/ }\end{array}$ & $\begin{array}{c}\text { Cutting } \\
\text { depth/mm }\end{array}$ & $\begin{array}{c}\text { Mean cutting } \\
\text { force/N }\end{array}$ & $\begin{array}{c}\text { Peak cutting } \\
\text { force/N }\end{array}$ \\
\hline 10 & 5 & 55.2 & 148.84 \\
10 & 10 & 121.65 & 257.46 \\
10 & 15 & 159.17 & 393.33 \\
5 & 10 & 132.82 & 279.42 \\
10 & 10 & 121.65 & 257.46 \\
15 & 10 & 110.95 & 219.94 \\
\hline
\end{tabular}

As shown in Figures 8 and 9, after the cutter came into contact with the coal rock, the cutting force exhibited a continuous fluctuation, as the chippings were peeled off all the time. Because the cutting parameters are constant, the mean cutting force gradually stabilized.

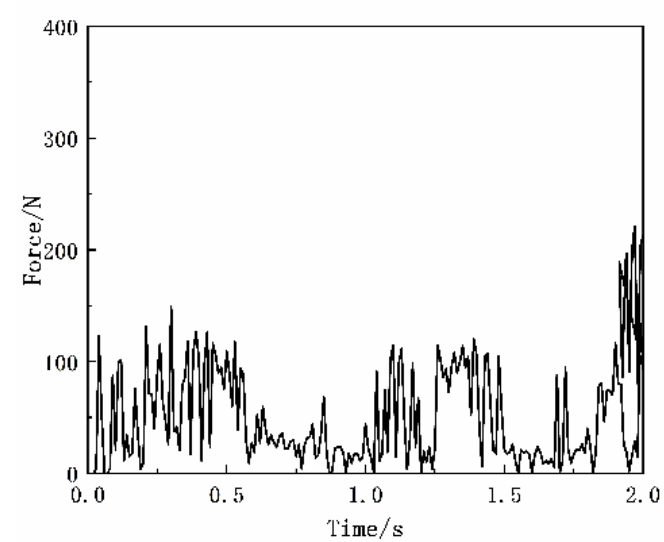

(a) Cutting depth: $5 \mathrm{~mm}$

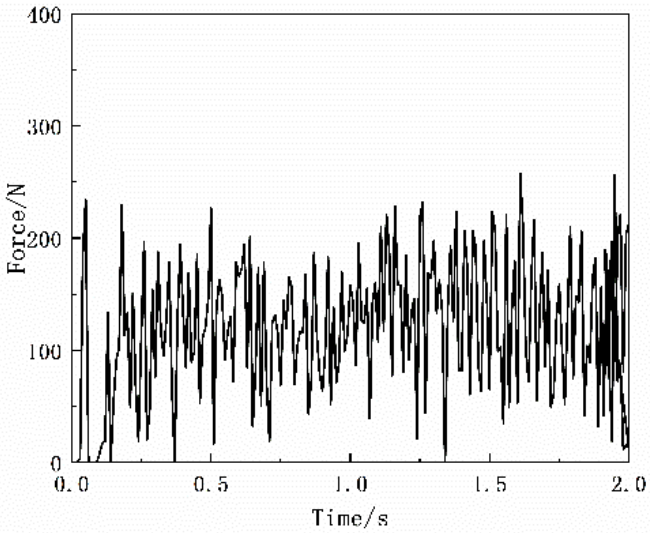

(b) Cutting depth: $10 \mathrm{~mm}$

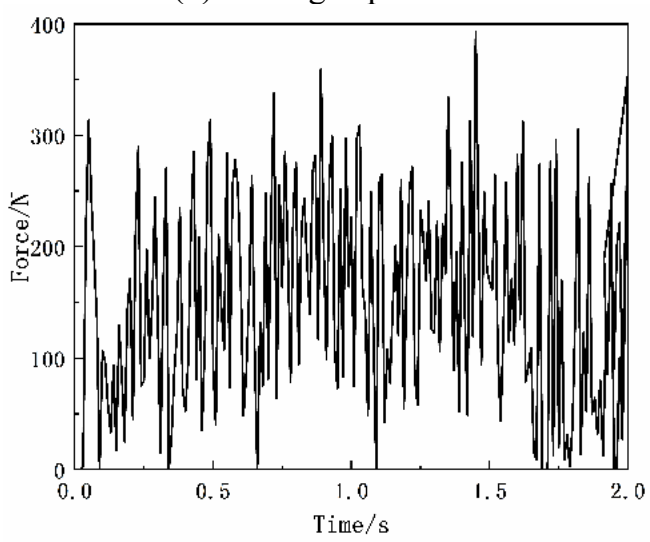

(c) Cutting depth: $15 \mathrm{~mm}$

Figure 8. Variation in cutting force with cutting depths

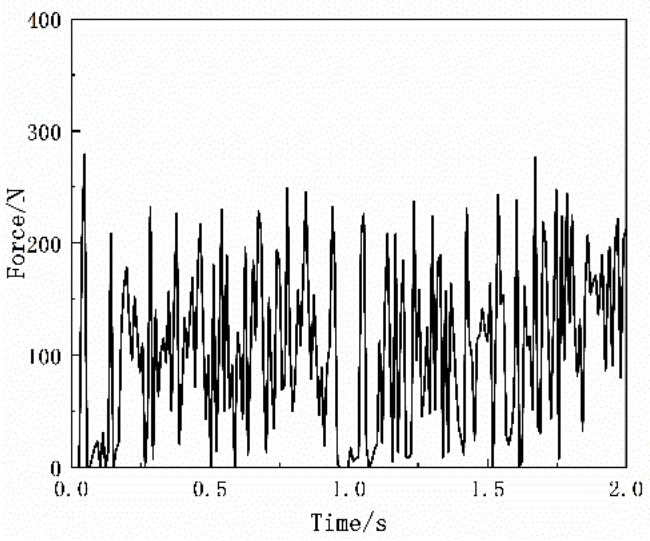

(a) Rake angle: $5^{\circ}$ 


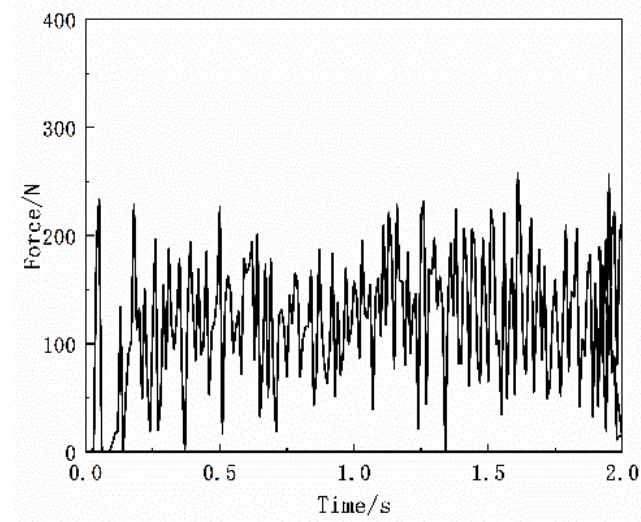

(b) Rake angle: $10^{\circ}$

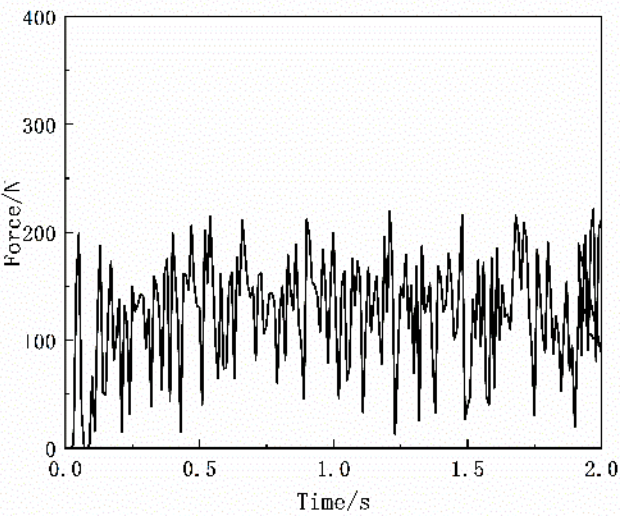

(c) Rake angle: $15^{\circ}$

Figure 9. Variation in cutting force with rake angles

It can be seen from Table 2 that, as the cutting depth increased from 5 to $15 \mathrm{~mm}$, the mean cutting force rose from 55.2 to $149.17 \mathrm{~N}$ and the peak cutting force climbed from 148.84 to $393.33 \mathrm{~N}$. Both the mean and peak of cutting force increased with the cutting depth. This means increasing the cutting depth could intensify the instability and fracturing of coal rock, despite the possibility of improving the tunneling efficiency. The greater the cutting depth is, the more nonuniform the chipping size, and the more prominent the phenomenon of discontinuous cutting. To rationalize the tunneling parameters, the cutting depth of coalmine rescue channels should be adjusted in real time, according to the stability of the coalface.

It can also be seen from Table 2 that, when the rake angle was $5^{\circ}$, the mean and peak cutting forces were 134.82 and $279.42 \mathrm{~N}$, respectively; when the rake angle widened to $10^{\circ}$, the mean and peak cutting forces decreased to 128.65 and $257.46 \mathrm{~N}$, respectively; when the rake angle further grew to $15^{\circ}$, the mean and peak cutting forces dropped to 120.95 and $219.94 \mathrm{~N}$, respectively. Overall, both the mean and peak of cutting force decreased with the growth in the rake angle. Hence, a large rake angle could enhance tunneling safety at the cost of efficiency. The rake angle is a design parameter of the cutter-head, and thus not changeable in the cutting process. Therefore, it is more reasonable to design a large rake angle for the cutter-head.

To sum up, the cutting depth of $10 \mathrm{~mm}$ and rake angle of $15^{\circ}$ are the optimal parameters for efficient and safe TBM tunneling.

\subsection{Comparison between simulation and model results}

To verify its effectiveness, our simulation model was compared with the Evans' model. Figure 10 compares the relationships between mean cutting force and cutting depth obtained by the two models at the rake angle of $10^{\circ}$; Figure 11 contrasts the relationships between mean cutting force and rake angle obtained by the two models at the cutting depth of $10 \mathrm{~mm}$. In the two figures, the model value refers to the mean theoretical cutting force computed by Eq. (13) in the Evans' model; the simulation value refers to the mean cutting force simulated by our model.

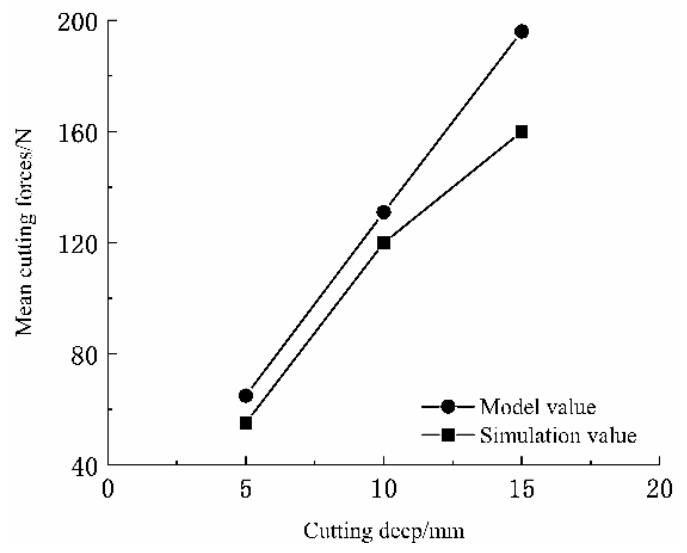

Figure 10. Variations in mean cutting force with cutting depths

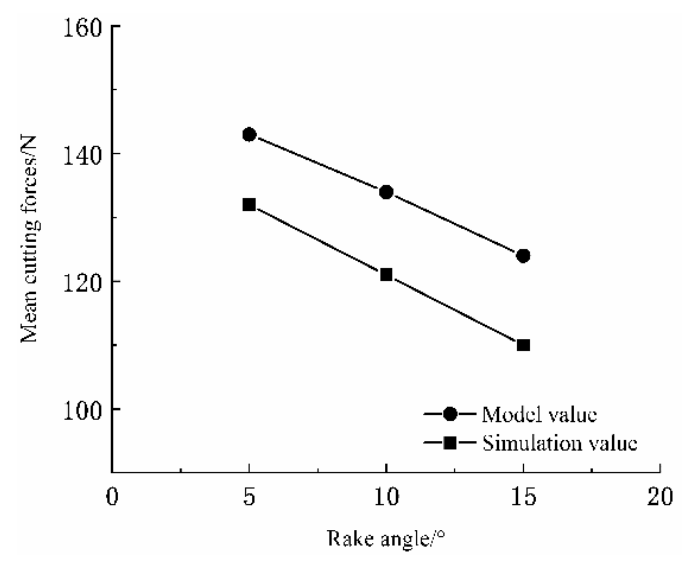

Figure 11. Variations in mean cutting force with rake angles

As shown in Figure 10, the model value and simulation value both increased linearly with the cutting depth. The simulation value was smaller than the model value, because the Evans' model only considers the cutting force in the stationary state. However, the cutting is discontinuous due to the continuous peeling of chippings. The deviation between the model value and simulation value was $10.2 \mathrm{~N}$ at the cutting depth of $5 \mathrm{~mm}$, and $36.1 \mathrm{~N}$ at the cutting depth of $15 \mathrm{~mm}$. This means, as the cutting depth increases, the chippings grow in size, and the cutting becomes more and more discontinuous. The increase in the deviation is consistent with the actual scenario of TBM tunneling.

As shown in Figure 11, the model value and simulation value both decreased linearly with the growth in the rake angle. The deviation between the model value and simulation value was $11.2 \mathrm{~N}$ at the rake angle of $5^{\circ}$, and $14.2 \mathrm{~N}$ at the rake angle of $15^{\circ}$. The discontinuity of the cutting process increases with the rake angle. That is why the simulation value was always smaller than the model value, and the deviation between them increased with the rake angle. 


\section{CONCLUSIONS}

This paper simulates the TBM cutting of coal rock on ABAQUS, focusing on the deformation, tearing and peeling of coal rock under the action of cutter. Compared with the cutting of soft rock, the TBM cutting of coal rock has unique features in rock-breaking and stress distribution and evolution.

Through the simulations, the authors observed the variations in cutting force with cutting depths and rake angles. The observations show that, as the cutting depth increased from 5 to $15 \mathrm{~mm}$, the mean cutting force grew from 55.2 to $159.17 \mathrm{~N}$, and the peak cutting force rose from 148.84 to $393.33 \mathrm{~N}$; as the rake angle widened from 5 to $15^{\circ}$, the mean cutting force dropped from 132.82 to $110.95 \mathrm{~N}$, and the peak cutting force declined from 279.42 to $219.94 \mathrm{~N}$. Therefore, a high cutting depth and a small rake angle are conducive to tunneling efficiency, while a small cutting depth and a large rake angle are beneficial to tunneling safety. To strike a balance between efficiency and safety, the optimal cutting parameters were determined as the cutting depth of $10 \mathrm{~mm}$ and the rake angle of $15^{\circ}$.

Finally, the simulation results were compared with the results obtained by Evans' model. The comparison shows that the simulation value exhibited the same trends with the model value, with a deviation of less than $10 \%$. Considering the discontinuities and impacts of the cutting process, our simulation method is highly applicable to real-world engineering projects. Our research fully discloses the coal rock-breaking mechanism of TBM cutters, making it easy to quantify the relationship between the rock-breaking performance and tunneling performance of TBM cutters. The research results lay a theoretical basis for the TBM tunneling of coalmine rescue channels.

\section{ACKNOWLEDGEMENTS}

This work is grateful to the financial supports from National Key R\&D Program of China (No. 2018YFC0808205), Liaoning Natural Science Foundation (No. 20180551017).

\section{REFERENCES}

[1] Deshmukh, S., Raina, A. K., Murthy, V.M.S.R., Trivedi, R., Vajre, R. (2020). Roadheader-A comprehensive review. Tunnelling and Underground Space Technology, 95: 103148. https://doi.org/10.1016/j.tust.2019.103148

[2] Reinsch, T., Paap, B., Hahn, S., Wittig, V., van den Berg, S. (2018). Insights into the radial water jet drilling technology - application in a quarry. Journal of Rock Mechanics and Geotechnical Engineering, 10(2): 236248. https://doi.org/10.1016/j.jrmge.2018.02.001

[3] Khan, N., Abas, N., Kalair, A. (2015). Pulsed and continuous wave $(\mathrm{CW})$ lasers in the oil, gas, coal and ignition industries. Lasers in Engineering, 30(3-4): $137-$ 157.

[4] Li, M., Han, B., Zhang, Q., Zhang, S., He, Q. (2019). Investigation on rock breaking for sandstone with high power density laser beam. Optik, 180: 635-647. https://doi.org/10.1016/j.ijleo.2018.10.059

[5] Badescu, M., Bar-Cohen, Y., Sherrit, S., Bao, X., Jackson, S., Metz, B., Simonini, A., Zacny, K., Mellerowicz, B., Kim, D., Paulsen, G.L. (2018). Auto- gopher-2-an autonomous wireline rotary piezopercussive deep drilling mechanism. Sensors and Smart Structures Technologies for Civil, Mechanical, and Aerospace Systems 2018, 10598: 105982W. https://doi.org/10.1117/12.2294560

[6] Huang, J., Wang, H., Ji, G., Zhao, F., Ming, R., Hao, Y. (2018). The rock breaking mechanism of ultrasonic high frequency rotary-percussive drilling technology. Petroleum Drilling Techniques, 46(4): 23-29.

[7] Huang, X., Liu, Q., Shi, K., Pan, Y., Liu, J. (2018). Application and prospect of hard rock TBM for deep roadway construction in coal mines. Tunnelling and Underground Space Technology, 73: 105-126. https://doi.org/10.1016/j.tust.2017.12.010

[8] Wu, L., Li, X., Guan, T., Qu, F., Zhang, J. (2017). Method for evaluating the driving performance of a cutterhead system of a shield machine. Modern Tunnelling Technology, 54(5): 108-114, 121. https://doi.org/10.13807/j.cnki.mtt.2017.05.015

[9] Cardu, M., Iabichino, G., Oreste, P., Rispoli, A. (2017). Experimental and analytical studies of the parameters influencing the action of TBM disc tools in tunnelling. Acta Geotechnica, 12(2): 293-304. https://doi.org/10.1007/s11440-016-0453-9

[10] Sun, H., Guo, W., Liu, J., Song, L., \& Liu, X. (2018). Layout design for disc cutters based on analysis of TBM cutter-head structure. Journal of Central South University, 25(4): 812-830. https://doi.org/10.1007/s11771-018-3786-8

[11] Liu, W., Qian, X., Li, T., Zhou, Y., Zhu, X. (2019). Investigation of the tool-rock interaction using DruckerPrager failure criterion. Journal of Petroleum Science and Engineering, 173 : https://doi.org/10.1016/j.petrol.2018.09.064

[12] Qiao, S., Xia, J., Xia, Y., Liu, Z., Liu, J., Wang, A. (2019). Establishment of coal-rock constitutive models for numerical simulation of coal-rock cutting by conical picks. Periodica Polytechnica Civil Engineering, 63(2): 456-464. http://dx.doi.org/10.3311/PPci.13084

[13] Gu, R., Ozbay, U. (2015). Numerical investigation of unstable rock failure in underground mining condition. Computers and Geotechnics, 63: 171-182. https://doi.org/10.1016/j.compgeo.2014.08.013

[14] Menezes, P.L., Lovell, M.R., Avdeev, I.V., Lin, J.S., Higgs Iii, C.F. (2014). Studies on the formation of discontinuous chips during rock cutting using an explicit finite element model. International Journal of Advanced Manufacturing Technology, 70(1-4): 635-648. https://doi.org/10.1007/s00170-013-5309-y

[15] Li, G., Wang, W., Jing, Z., Zuo, L., Wang, F., Wei, Z. (2018). Mechanism and numerical analysis of cutting rock and soil by TBM cutting tools. Tunnelling and Underground Space Technology, 81: 428-437. https://doi.org/10.1016/j.tust.2018.08.015

[16] Rostami, J., Chang, S. (2017). A closer look at the design of cutterheads for hard rock tunnel-boring machines. Engineering, 3(6): 892-904. https://doi.org/10.1016/j.eng.2017.12.009

[17] Innaurato, N., Oggeri, C., Oreste, P.P., Vinai, R. (2007). Experimental and numerical studies on rock breaking with TBM tools under high stress confinement. Rock Mechanics and Rock Engineering, 40(5): 429-451. https://doi.org/10.1007/s00603-006-0109-4

[18] Geng, Q., Wei, Z., Meng, H., Macias, F.J., Bruland, A. 
(2016). Free-face-assisted rock breaking method based on the multi-stage tunnel boring machine (TBM) cutterhead. Rock Mechanics and Rock Engineering, 49(11): 4459-4472. https://doi.org/10.1007/s00603-0161053-6

[19] Farrokh, E., Kim, D.Y. (2018). A discussion on hard rock TBM cutter wear and cutterhead intervention interval length evaluation. Tunnelling and Underground Space Technology, 81: 336-357. https://doi.org/10.1016/j.tust.2018.07.017

[20] Bilgin, N., Copur, H., Balci, C. (2012). Effect of replacing disc cutters with chisel tools on performance of a TBM in difficult ground conditions. Tunnelling and Underground Space Technology, 27(1): 41-51. https://doi.org/10.1016/j.tust.2011.06.006

[21] Cho, J., Jeon, S., Yu, S., Chang, S. (2010). Optimum spacing of TBM disc cutters: A numerical simulation using the three-dimensional dynamic fracturing method. Tunnelling and Underground Spactechnology, 25(3): 230-244. https://doi.org/10.1016/j.tust.2009.11.007

[22] Maji, V.B., Theja, G.V. (2017). A new performance prediction model for rock TBMs. Indian Geotechnical
Journal, 47(3): 364-372. https://doi.org/10.1007/s40098017-0226-X

[23] Rojek, J. (2014). Discrete element thermomechanical modelling of rock cutting with valuation of tool wear. Computational Particle Mechanics, 1(1): 71-84. https://doi.org/10.1007/s40571-014-0008-5

[24] Munoz, H., Taheri, A., Chanda, E. (2016). Rock cutting characteristics on soft-to-hard rocks under different cutter inclinations. International Journal of Rock Mechanics and Mining Sciences, 100(87): 85-89. https://doi.org/10.1016/j.ijrmms.2016.05.014

[25] Evans, I. (1984). A theory of the cutting force for pointattack picks. International Journal of Mining Engineering, 2: 63-71. https://doi.org/10.1007/BF00880858

[26] Alejano, L.R., Bobet, A. (2012). Drucker-Prager criterion. Rock Mechanics and Rock Engineering, 45(6): 995-999. https://doi.org/10.1007/s00603-012-0278-2

[27] Moran, D.A., Pantelides, C.P., Reaveley, L.D. (2019). Mohr-coulomb model for rectangular and square FRPconfined concrete. Composite Structures, 209: 889-904. https://doi.org/10.1016/j.compstruct.2018.11.024 